doi: $10.15407 /$ ujpe62.04.0294

A.B. BORDYUH

National Aviation University

(1, Prosp. Komarova, Kyiv 03058, Ukraine; e-mail: a.bordyuh@gmail.com)

\title{
MECHANISM OF DIMERIZATION
} OF VIOLOGENS IN LIQUID CRYSTALLINE MEDIUM

\section{Introduction}

Works devoted to the investigation of chemical and physical properties of nonconventional classes of liquid crystals (LC) significantly extend the range of fundamental knowledge on these materials, which include organosilicon compounds [1, 2], Schiff base metal complexes [3, 4], and ionic thermotropic and lyotropic liquid crystals of metal alkanoates. While thermotropic liquid crystals, when being in the mesophase or glassed mesophase $[5,6]$, have significant optical absorption in the visible region, metal alkanoates that form the lyotropic liquid crystalline phase generally do not absorb. To provide liquid crystalline materials with desired optical properties, one needs to combine lyotropic ionic liquid crystals (LILC) and different impurities, namely polymethine dyes [7], viologens, etc. Particularly, the introduction of photo- and electrochromic impurities such as viologens allows creating materials with optical properties that could be regulated, by using the ultraviolet irradiation or application of an external electric field. Structural and electrooptical peculiarities

(C) A.B. BORDYUH, 2017

294 of such materials were previously investigated in a number of works [8-10]. Possible practical applications require a further specification of intermolecular processes taking place under the action of an electric field and causing color modifications of interest.

The present work discloses the possible mechanism of reduction and dimerization of viologen molecules introduced into a lyotropic ionic liquid crystalline medium under the action of an electric field.

\section{Experimental Methods and Materials}

The lyotropic ionic liquid crystalline phase was formed by mixing a powder of a potassium caprylate $\left(\mathrm{C}_{7} \mathrm{H}_{15} \mathrm{COO}^{-} \mathrm{K}^{+}\right)$with water in the $1: 1$ weight proportion at room temperature. LILC samples were doped by $\mathrm{N}, \mathrm{N}^{\prime}$-diheptyl-4,4'-dipyridilium dibromide $\left(\mathrm{HD}^{2+} 2 \mathrm{Br}^{-}\right)$viologen with the general structural formula shown in Fig. 1. The viologen content in LILC samples amounts to $2 \%$ by weight.

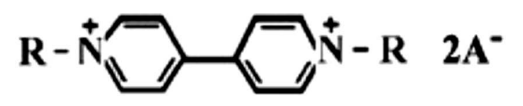

Fig. 1. General structural formula of $\mathrm{HD}^{2+} 2 \mathrm{Br}^{-}$viologen. $R$ is a substitute $\left(\mathrm{C}_{7} \mathrm{H}_{15}\right), A$ is a counterion $\left(\mathrm{Br}^{-}\right)$

ISSN 2071-0194. Ukr. J. Phys. 2017. Vol. 62, No. 4 
(a)

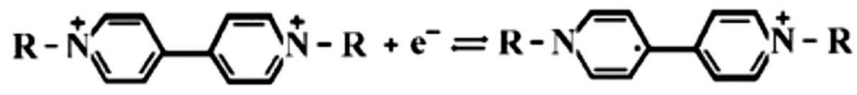

(b)

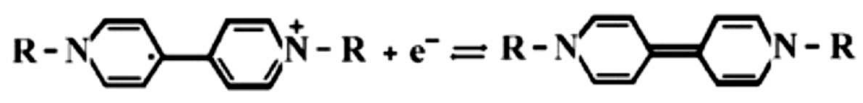

(c)

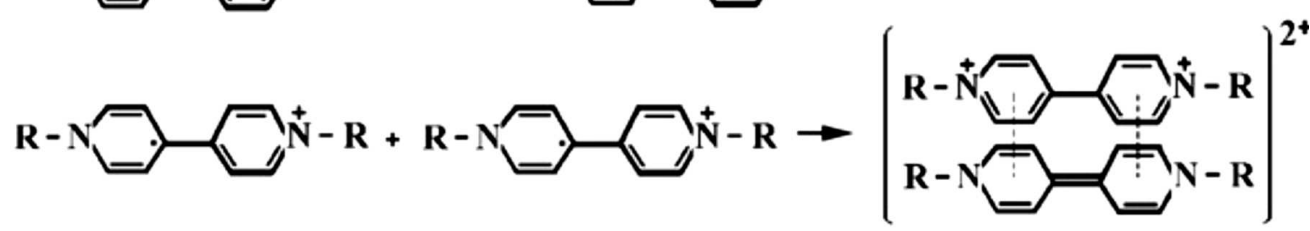

(d)

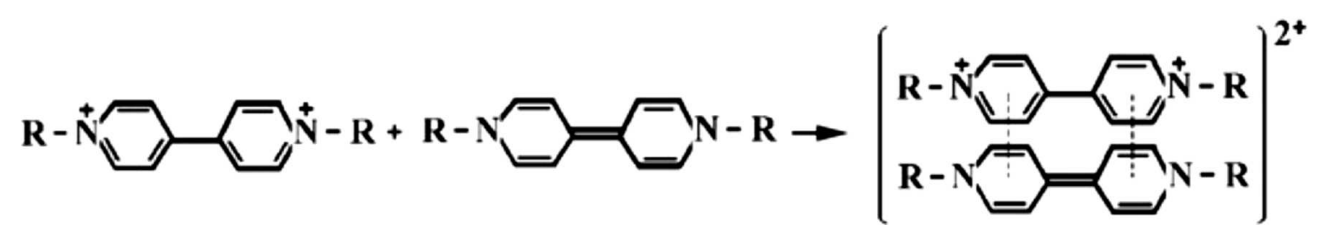

Fig. 2. Schemes of reduction and dimerization of a viologen molecule under the action of an electric field. Oneelectron reduction and formation of a radical cation $(a)$. Two-electron reduction and formation of a biradical (b). Dimerization due to the radical cation - radical cation interaction $(c)$. Dimerization due to the interaction between initial and fully reduced viologen molecules $(d)$

It is worth to note that other viologen species could be used to dope liquid crystals on the base of potassium caprylate, as well as other homologs of potassium salts could be used as LC matrices. The similarity between sizes of the water-containing electrostatic layer of a liquid crystal and viologen's core allows viologens to build organically into the LC matrix without breaking its ordering [8].

Sandwich cells with their inner surface covered with ITO electrodes were used for the investigation of LILC - viologen samples. The cells were pasted to avoid the air access and the further spoiling of samples. The thickness of the sample was set with using teflon pads. The voltage was applied by using a constant voltage source. The visible absorption spectra of samples exposed to the action of an electric field at different voltage values were obtained with using a spectrometer based on a monochromator MDR-6.

\section{Results and Discussion}

It is known that the application of an electric field leads to the reduction of viologen molecules and the formation of colored radical cations and dimers [1115]. Investigations of volt-ampere characteristics of LILC - viologen samples [10] showed that, in the lyotropic liquid crystalline medium $\mathrm{HD}^{2+} 2 \mathrm{Br}^{-}$, viologen reduces under the action of an electric field in two stages. On the first stage, a viologen molecule turns into a blue-colored radical cation (Fig. 2, a). On the second stage, the radical cation reduces to a colorless biradical with plane quinoid structure (Fig. 2, $b$ ). The further dimerization could be stipulated by two different processes. According to work [11], the dimerization of viologens in water is caused by the interaction between two radical cations (Fig. 2, c), when their concentration in a sample reaches some critical value. In more recent works, the dimerization is associated with the interaction between initial viologen molecules and molecules that undergone the two-electron reduction (Fig. 2, d) [13-15].

The information received from the voltamperometry experiment was justified and completed by the optical spectrometry data. Figure 3 shows the main stages of the viologen transformation under conditions of the application of the increasing voltage. In the initial state, LILC - viologen samples do not absorb in the visible region (Fig. 3, curve 1). After applying the voltage $U=2.5 \mathrm{~V}$, the one-electron reduction of viologen molecules led to the formation of blue-colored radical cations, whose presence was confirmed by the characteristic absorption band at $\lambda=605 \mathrm{~nm}$ (Fig. 3, curve 2). The two-electron reduction was observed at $U=3 \mathrm{~V}$ and characterized by the absorption spectrum (Fig. 3, curve 3) showing no significant absorbance. The dimerization occurred after increasing the voltage up to $4 \mathrm{~V}$ and was 


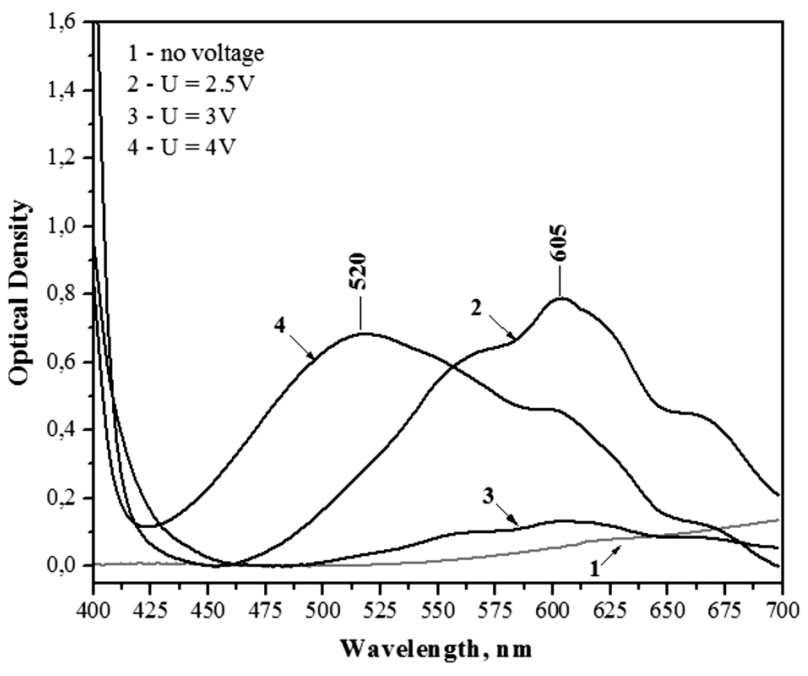

Fig. 3. Absorption spectrum of the LILC - viologen sample. Curve $1-U=0 \mathrm{~V}$; curve $2-U=2.5 \mathrm{~V}$; curve $3-U=3 \mathrm{~V}$; curve $4-U=4 \mathrm{~V}$

confirmed by the characteristic absorption band with $\lambda=520 \mathrm{~nm}$ (Fig. 3, curve 4). Similar color change was observed, when the voltage increase step was reduced to the tenth of one volt.

The lifetime of colored viologen derivatives, radical cations, and dimers may vary and lasts from seconds to days depending on the magnitude and duration of the voltage applied. In general, these colored viologen products can be relatively stable for using them in applications such as the diffraction grating recording $[9,10]$. However, it was discovered that the colorless form of a biradical is very unstable. After switching-off the voltage, the colorless samples quickly became blue-colored. The last fact indicates the back transformation of biradicals to radical cations. On the other hand, the further increase of the voltage led to the dimerization.

According to the data obtained, the dimerization cannot be caused by the radical cation - radical cation interaction, since there are no radical cations in the sample at voltages exceeding $3 \mathrm{~V}$. This was clearly shown by the absorption spectra, as well as by the presence of an intermediate stage between the formation of radical cations and dimers. The liquid crystalline medium, which has much greater viscosity than water, allowed us to separate distinctly all the viologen transformation phases. This allows also extending the lifetime of colored products in comparison with water and other liquid media [14].
One more effect of the liquid crystalline matrix and the geometry of sandwich cells used in the experiments consists in the following: all the reduction processes and the further dimerization took place in the near-cathode region, where viologen molecules could capture free electrons. As a result, the initially homogeneous samples underwent a separation into a bilayered structure, which consists of a colored layer of viologen reduction products and an LC layer. The experiments on circular dichroism have shown that the layer of colored viologen derivatives is highly ordered, since the movement of viologen molecules is restricted by the LC matrix. Assume that all viologen molecules at a given concentration are precipitated on the cathode. Then the maximal width of the colored layer was evaluated to be approximately $400 \mathrm{~nm}$.

However, the absorptive viologen layer is much thinner de facto; therefore, initial or non-reduced viologen molecules are still present in the volume of a sample even after applying the voltage. Under the action of an increased voltage $(>3 \mathrm{~V})$, they can freely move along electrostatic layers of the liquid crystal toward the electrode. Since there is a layer of double reduced biradicals on the cathode, molecules coming from the volume of a sample can interact with fully reduced molecules, thereby forming dimers. This proves the fact that, in the liquid crystalline medium, the way of dimerization is similar to the way described in [13-15].

Taking into account that the processes of formation of radical cations and dimers take place in a thin layer near the cathode, it is possible to consider, as the first approximation, this layer as a solid crystalline layer. So, the abovementioned processes could be analyzed from the point of view of the theory of molecular crystals [16].

The dimerization of viologen molecules is connected with the formation of the so-called physical dimers. Physical dimers are formed in the case of two equal molecules, which are located closer to each other than to other similar molecules and have specific orientation. At the same time, they do not form any chemical bond with each other.

If the dimer is in a stationary state the excitation is distributed between two molecules for all the time. If the dimer exists in a non-stationary state, i.e., the excitation is localized at one molecule, provided that there is no energy removal, the excitation is transferred from one molecule to another one in 

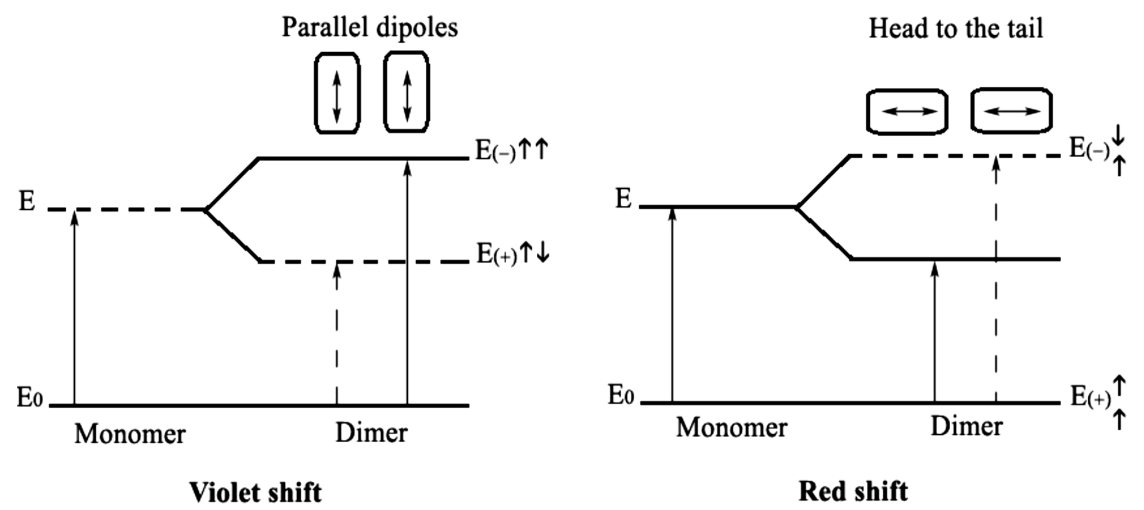

Fig. 4. Exciton zone splitting and the shift of energy levels for a physical dimer. Two possible optical transitions are shown by arrows

a wavelike or coherent manner. This leads to a shift and a splitting of the energy levels of a dimer relative to the levels of a monomer. The shift of spectral bands can occur toward the violet or red spectral region. It depends on the values of Coulomb binding energy of a pair of monomers and Coulomb energy of interaction between distributed charges of the first monomer and the second one, being in the excited and ground states, respectively, and on the mutual orientation of transition moments of these monomers. The allowed dipole transitions are defined by transition moments, which are equal for the "plus" and "minus" dimeric states. In the case of translation-equivalent molecules, these moments can be parallel or antiparallel. Therefore, for one of the configurations, the resulting moment is equal to zero. In other words, the optical transition is allowed only to the one excited state of a dimer (Fig. 4).

Applying the foregoing theory to the experimental results, it is possible to assume the mechanism of formation of dimers by viologen molecules. According to the optical spectra, the absorption of a dimeric form of viologen is shifted to the violet region relative to the absorption of radical cations (Fig. 3). Thus, during the formation of dimers, the molecules are situated in parallel to each other, as it is shown in Fig. 4. In this case, the excitation transition between antiparallel molecules is forbidden, so the formation of a dimer by two radical cations is excluded. Therefore, in the case of viologens, the dimers can be formed only due to the donor-acceptor interaction between a fully reduced viologen molecule with quinoid structure and the initial molecule, as described, for example, in [13].
The established mechanism of dimerization of viologens in the liquid crystalline medium could be generalized onto other water-containing viscous media and is important for possible practical applications, for example, for determining the voltage value required for the desired color change of a viologencontaining material. Furthermore, the understanding of a nature of viologen dimerization can be useful for determining the origin of nonlinear optical effects observed in colored LILC - viologen samples.

\section{Conclusions}

1. Experimental data obtained by means of optical spectrometry have shown that, during the gradual increase of the voltage applied to the LILC - viologen samples, viologen molecules undergo two stages of reduction with the formation of blue-colored radical cations and colorless biradicals, respectively, followed by the stage of the formation of red-colored dimers after a further increase of the voltage.

2 . The application of the quantum theory of molecular crystals to the viologen dimerization process indicates that, according to the observed shift of the absorption band of a dimeric form of viologen toward the violet spectral region relative to the absorption band of radical cations, the dimerization can occur only between two parallel molecules. This corresponds to the dimerization due to the interaction between fully reduced and initial viologen molecules.

3. These facts together clearly define that, in a lyotropic liquid crystalline medium and in other watercontaining viscous media, the formation of dimers 
involves the interaction between viologen molecules that undergone the two-electron reduction and initial viologen molecules.

1. T.V. Timofeeva, E.E. Boda, A.P. Polischuk, M.Yu. Antipin, E.V. Matukhina, I.M. Petrova, N.N. Makarova, Yu.T. Struchkov. Structure investigations of thermotropic liquid crystalline monomer and polymer organosilicon compounds. Mol. Cryst. Liq. Cryst. 248, 125 (1994) [DOI: 10.1080/10587259408027173].

2. A.P. Polishchuk, N.N. Makarova, T.V. Astapova. X-ray diffraction investigation of trans-2,8-dihydroxy-2,8-diphenyl- $4,4^{\prime}, 6,6^{\prime}, 10,10^{\prime}, 12,12^{\prime}$-octamethylcyclohexasiloxane and trans-2,8-dihydroxy-2,4,4',6,6 $6^{\prime}, 8,10,10^{\prime}, 12,12^{\prime}$-decamethyl-5-carbohexacyclosiloxane. Kristallografiya 47, 863 (2002).

3. A.P. Polishchuk, T.V. Timofeeva. Metal-containing liquidcrystal phases. Russian Chem. Rev. 62, 291 (1993) [DOI: 10.1070/RC1993v062n04ABEH000019].

4. L.M. Babkov, N.A. Golovina, A.V. Kosov, A.P. Polishchuk, G.A. Puchkovskaya. Molecular structure and conformation changes of mesogen crystals. J. Molec. Struct. 218, 207 (1990) [DOI: 10.1016/0022-2860(90)80268-O].

5. A.V. Gridyakina, Yu.A. Garbovskiy, G.V. Klimusheva, A.P. Polishchuk. Nonlinear optical response of smectic glasses based on cobalt alkanoates. Ukr. J. Phys. 57, 177 (2012).

6. G.V. Klimusheva, Yu. Garbovskii, S. Bugaichuk, A.S. Tolochko, A.V. Gridyakina, A.P. Polishchuk, T.A. Mirnaya. Novel nanocomposite materials based on mesomorphic glasses of metal alkanoates: structure and nonlinear optical properties. High Energy Chem. 43, 532 (2009) [DOI: 10.1134/S0018143909070042].

7. S. Bugaychuk, G. Klimusheva, Yu. Garbovskiy, T. Mirnaya, A. Ischenko. Nonlinear optical properties of composites based on conductive metal-alkanoate liquid crystals. Opto-Electron. Rev. 14, 275 (2006) [DOI: 10.2478/s11772006-0036-7].

8. A.B. Bordyug, A.P. Polishchuk, G.V. Klimusheva, A.S. Tolochko, T.A. Mirnaya, G.G. Yaremchuk. Structure and intermolecular interactions in ionic liquid crystals doped with electrochromic viologen. Russian J. of Phys. Chem. 79, 866 (2005).

9. A. Bordyuh, Yu. Garbovskiy, S. Bugaychuk, G. Klimusheva, V. Reshetnyak. Fast nonlinear optical mechanisms in bi-layered cells composed by lyotropic ionic liquid crystals with dye and viologen films. Mol. Cryst. Liq. Cryst. 508, 296 (2009) [DOI: 10.1080/15421400903065788].
10. A.B. Bordyuh, Yu.A. Garbovskiy, S.A. Bugaychuk, G.V. Klimusheva, T.A. Mirnaya, G.G. Yaremchuk, A.P. Polishchuk. Dynamic grating recording in lyotropic ionic smectics of metal alkanoates doped with electrochromic impurities. Opt. Mat. 31, 1109 (2009) [DOI: 10.1016/ j.optmat.2008.11.021].

11. E.M. Kosower, J.L. Cotter. Stable free radicals. II. The reduction of 1-methyl-4-cyanopiridinium ion to methylviologen cation radical. J. Amer. Chem. Soc. 86, 5524 (1964).

12. V.N. Gratchev, S.I. Zhdanov, G.S. Supin. The investigation of chemical properties of bis-(0,0-dimethylphosphate)$\mathrm{N}, \mathrm{N}^{\prime}$-dimethyl-4,4-dipyridilium using methods of classic and alternating current polarography. Electrochem. XIV, 1353 (1978).

13. P.M.S. Monk, R.D. Fairweather, M.D. Ingram, J.A. Duffy. Pulsed electrolysis enhancement of electrochromism in viologen systems: influence of comproportionation reactions. J. Electroanal. Chem. 359, 301 (1993).

14. P.M.S. Monk. The Viologens: Physicochemical Properties, Synthesis and Applications of the Salts of 4,4'-Bipyridine (Wiley-VCH, 1998) [ISBN: 978-0-471-98603-4].

15. P.M.S. Monk, N.M. Hodgkinson, R.D. Partridge. The colours of charge-transfer complexes of methyl viologen: effects of donor, ionic strength and solvent. Dyes and Pigments. 43, 241 (1999).

16. M. Pope, C.E. Swenberg. Electronic Processes in Organic Crystals (Clarendon Press, 1982) [ISBN: 9780195129632].

Received 07.09.15

\section{Г.Б. Бордюг}

МЕХАНІЗМ ДИМЕРИЗАЦІЇ ВІОЛОГЕНІВ У РІДКОКРИСТАЛІЧНОМУ СЕРЕДОВИЩІ

$\mathrm{P}$ е $з$ ю м е

У даній роботі наведено аналіз експериментальних даних 3 електрооптичних властивостей віологенів, унесених у рідкокристалічне середовище в ролі домішок. Ці дані разом iз теоретичними міркуваннями дозволили визначити механізм, який приводить по подвійної зміни забарвлення у зразках рідкий кристал-віологен, викликаної прикладанням зростаючої напруги. Зокрема, було доведено, що перша зміна забарвлення відбувається завдяки одноелектронному відновленню молекул віологенів, а друга зміна забарвлення спричинена димеризацією між молекулами віологенів, які були повністю відновлені під дією прикладеної напруги, та вихідними молекулами віологенів. 